J. Clin. Chem. Clin. Biochem.

Vol. 25, 1987, pp. 753-757

(C) 1987 Walter de Gruyter \& Co. Berlin - New York

\title{
Radioimmunological Hair Analysis for Narcotics and Substitutes
}

\author{
By W. Arnold \\ Forensic Laboratories Hamburg
}

(Received January 10/June 18, 1987)

Summary: In recent years it has become possible to detect organic pharmaceuticals and poisons in a few milligrams of hair, using radioimmunological methods. Some methods are specific for individual compounds, others for groups of compounds. This is of great importance inter alia for forensic purposes, especially in cases of drug abuse. With the help of such hair analysis it is possible to trace the drug career of an addicted person for up to one year, and in certain cases for a longer period. Frequently, the results provide information on events in the rather distant past. This can be of considerable anamnestic and forensic importance.

\section{Introduction}

Hair as a human dermal appendage consists of a relatively homogeneous biological substrate. Being easily accessible it is particularly suitable as a material for analysis. In a further sense the biological-chemical composition of hair reflects the metabolism of the individual, additionally influenced by environmental substances. Thus, the uptake of toxic trace elements from air or food can be determined by analysis of hair from the head without difficulty (1). Recently, it has been shown that the intake of organic pharmaceuticals can be detected by hair analysis $(2-5)$.

\section{Forensic Determinations}

Hair - found at the scene of a crime - can provide important circumstantial evidence for identification of a possible perpetrator and, by linkage to other results, may serve as a means of conviction or exculpation (6). Human and animal hair can be distinguished microscopically. Examination of hair roots frequently allows a differentiation of sexes. Furthermore it may be determined whether hairs are coloured, torn out, cut or have been exposed to physical or chemical influences. By microscopical comparison, similarities between hair samples, especially in the cuticula, can be established, e.g. between hair found at the scene of a crime and hair from a suspicious person $(7,8)$. Analysis of inorganic trace elements may provide indications of whether the concerned individual has been exposed to certain inorganic substances in air or food (9). Especially for arsenic, thallium and lead, results have been obtained, which, together with the rate of hair growth, allow calculation of time of uptake and in some cases the conviction of the perpetrator $(10=12)$. In recent years success has been reported in the serological determination of blood group antigens and types of enzymes in hair $(13,14)$.

\section{Hair Analysis for Organic Pharmaceuticals}

By means of modern analytical methods the detection of inorganic elements in human hair has become possible in the picogram range. Some elements in hair, such as arsenic, thallium and lead have been determined for decades by special methods $(10-12)$. Just a few years ago the analytical methods available were not yet sufficiently sensitive and specific to determine organic pharmaceuticals in hair.

In 1971 Forrest et al. (15) found an uptake of tritiated chlorpromazine and tetrahydrocannabinole in animal hair. Nearly ten years later Baumgartner et al. (5) in the USA and in Europe Klug (16) and Arnold, Püschel et al. (2, 3, 4, 17-19) first discovered opiates in human hair of the head by means of radioimmunological methods. In the course of further examination - carried out with radioimmunoassays (RIA) - phencyclidine (20), methaqualone (21), cocaine (22) and amphetamine (23) were identified and the results were partly verified by mass spectrometry and gas chromatography.

At the institute for forensic medicine of the university of Hamburg, hair from the head of corpses suspected of death caused by drugs is systematically examined for the presence of morphine as a catabolic product of heroin. Hair of living persons suspected of taking drugs is also examined.

Should it be necessary to confirm conclusions on the development of drug taking of individuals, the procedure is as follows:

A tuft with a surface of ca. $1 \mathrm{~cm}$ is cut close to the skin. It is important that the hairs are not displaced in their relative position to each other. The tuft is fixed by adhesive tape to a sheet of paper. The top and the end near the roots are marked: Taking growth into consideration (ca. $1 \mathrm{~cm} / \mathrm{month}$ ) the hairs can be divided into single segments in order to estimate the time the drug was taken and to provide indications about the so-called drug-career. The analysis of hair which is more than $6=8 \mathrm{~cm}$ in length (i. e. grown of 6-8 months) can lead to an unprecise chronological determination. In a few cases it was possible to trace a drug-career of up to one year and longer. 
Results could be verified by additional facts and evidence or by statements given by the drug-dependent individual concerned.

For a single RIA-analysis $20-50 \mathrm{mg}$ of hair will be used. This corresponds to ca 20-100 single hairs with a length of $1 \mathrm{~cm}$. In extreme cases, with a high content of medicaments, a few hairs are sufficient to obtain usable results, but a chronological estimation of a drug uptake is then difficult. With corpses in a state of progressed putrefaction and maximal loss of soft parts - especially by animal scavenging - hair of the head may often be the only preserved material that can be usefully analysed for suspicion of drug abuse.

\section{Pretreatment for RIA analysis}

First the portions of single hair segments are washed with acetone, then water and a second time with acetone to remove fatty substances, dust and corpuscular particles, as well as sodium chloride derived from perspiration. Between 10 and 20 percent, sometimes more, of inorganic trace elements may be lost. These substances are probably present as deposits on the outer layers.

Exogeneous uptake of organic medicaments is complicated because the large size of the molecule and other properties prevent their passage through outer surfaces of the hair. Penetration of the hair by large molecules is facilitated by a damaged cuticula $(24,25)$. Organic medicaments, incorporated endogeneously into hair protein will hardly be affected by washing procedures, and losses are minimal.

After addition of $1 \mathrm{ml} 1 \mathrm{~mol} / 1 \mathrm{NaOH}$, exactly $50 \mathrm{mg}$ of the cleaned portions of hair are repeatedly boiled in a heat resistant long glass centrifuge tube until the hair structure can no longer be recognized. Loss of fluid by steaming or splashing should be avoided. After cooling, the $\mathrm{pH}$ is adjusted to $\mathrm{pH} 6.5-7.5$ by addition of $1 \mathrm{~mol} / 1 \mathrm{HCl}$. Deviations from this procedure may result in denaturation of antisera and thus a simulation of false-positive results. By this alkaline hydrolysis, morphine is released from its linkage to hair proteins and may be determined. Presumably, morphine is bound to hair keratins in the same way as inorganic substances (26), but there is no firm evidence of this. Duplicate $(25 \mu \mathrm{leach})$ or in particular cases triplicate determinations are recommended, with calculation of the average. For the standard curve each point should be determined in triplicate. The result is multiplied by a factor of 40 to give the amount of morphine in the sample $(50 \mathrm{mg}$ of hairs).

\section{RIA analysis}

The radioimmunological estimation is performed according the recommended procedures of the different RIA kits. For increased accuracy the values from a hair analysis should be in the middle part of the standard curve. In the analysis for morphine with the RIA kit of Diagnostic Products Corporation (DPC, in the FRG delivered by: H. Biermann GmbH, Lindenstraße 16, D-6350 Bad Nauheim) it is recommended that the morphine-specifity of this kit should be tested by comparing analyses of standard morphine solutions with or without addition of a 400-500-fold concentration of codeine; similar or almost identical values should be obtained.

\section{Results}

With the establishment of hair analysis for medica-ments a few years ago, it is now possible to prove medicament abuse several months to one year later. This has added new dimensions to the field of forensic and clinical-toxicological analysis. Analyses of blood or urine still cannot produce comparable results. Blood or urine analyses show the current excretion of a drug and permit no further conclusions. For example, a low drug level in urine may mean that only a short time has elapsed since intake of the medicament, or it may mean that large quantities of the drug were taken more than 48-72 hours ago. Several investigators in this new field are of the opinion that the amounts of drugs in hair more precisely reflect the actual situation of drug consumption than the conventional urine and blood analysis does (5, $24,27)$.

\section{Examples}

The following two examples characterize the new possibilities offered by hair analysis in an exceptionally clear way:

1. Autopsy of a young woman found hanging in her apartment produced no further information, apart from the typical signs of hanging. The Hamburg Police Drug Department learned that this woman had been drug-dependent years ago, but had been virtually cured of heroin dependence. A chemicaltoxicological investigation of the organs and body fluids was negative. In hair from the head, as the following table 1 shows, a nearly continuously increasing morphine level was found from tip to root. Police later found that the young woman had relapsed slightly longer than one yearr before her death and had taken increasing amounts of heroin since then. Hair examination confirmed this factual situation.

Tab. 1. Opiate levels of different sections of hair samples (21 year-old addict woman, suicide by hanging).

\begin{tabular}{lll}
\hline Root & $3 \mathrm{~cm}$ & $3.2 \mathrm{mg} / \mathrm{kg}$ hair \\
& $3 \mathrm{~cm}$ & $1.6 \mathrm{mg} / \mathrm{kg}$ hair \\
& $3 \mathrm{~cm}$ & $2.1 \mathrm{mg} / \mathrm{kg}$ hair \\
& $3 \mathrm{~cm}$ & $1.2 \mathrm{mg} / \mathrm{kg}$ hair \\
& $3 \mathrm{~cm}$ & $0.1 \mathrm{mg} / \mathrm{kg}$ hair \\
Top & $3 \mathrm{~cm}$ & 0.0 \\
\hline
\end{tabular}

2. A polytoxicomanic male addict gave samples of his head hair for examination. He stated that four months earlier he had consumed large amounts of methaqualone, besides variable but smaller amounts of codeine, barbiturates and heroin. After declaration of methaqualone as a narcotic, this medicament was no longer obtainable on the drug market. This was verified by results from hair examination. There were high methaqualone values in distal parts, decreasing sharply in correlation with the declaration of this medicament as a narcotic. During this time, barbiturate and opiate values in more proximal hair parts increased moderately and remained at a certain level. 


\section{Additional studies}

Data, obtained from living or dead persons belonging to the drug scene, were to complemented and verified by results from volunteers and laboratory animals (guinea pigs). Several male patients took one dose of 100 or $200 \mathrm{mg}$ codeine. The codeine in single samples of urine was detected by gas chromatography and RIA. The opiate values from gas chromatography increased to ca. $12 \mathrm{mg} / \mathrm{l}$ after 24 hours and decreased to zero during the third day. The radioimmunological analysis produced similar results, but small amounts of opiates were detected at the beginning of the fourth day. Beard hair was collected daily, and the first traces of codeine were found 1-2 days after its intake. A maximal excretion in the beard hair of patients was found on the third day after intake, with values up to $5 \mathrm{mg} / \mathrm{kg}$. Traces of codeine in beard hair were detectable up to the beginning of the seventh day. Studies on guinea pigs gave results analogous to those obtained with humans. A direct comparison was impossible, because guinea pig hair does not grow as fast as human hair, and does not exceed a length of $2 \mathrm{~cm}$.

\section{Discussion}

For several years attempts have been made in forensic toxicology to verify results of chemical-toxicological studies by two further, independent methods. In the case of hair analysis the RIA results should be confirmed by mass spectrometry, and no additional, alternative procedure is available. In other fields of analytical chemistry, if a certain parameter can be determined only by immunological methods, the results would have a more or less limited value. In the absence of a second independent, routine method, RIA medicament detection in human hair will thus be interpreted with caution by many toxicological chemists. Even the high sensitivity of combined $\mathrm{GC} /$ MS is sometimes not sufficient, especially with a small amount of material. In particular the work-up and preparation of hair for a GC/MS analysis is timeconsuming and expensive, so that from the start it is burdened with considerably low precision.

For these reasons it is necessary to carry out immunological medicament analysis in hair only with specific and highly-sensitive RIA kits, for the selective estimation of a certain medicament, like morphine. The cross-reactivity must be so low that very similar substances will not be detected, or only in small amounts. This is valid for the RIA-Morphine Kit from Diagnostic Products Corporation (DPC). It is $400-500$ times less sensitive for codeine, which differs from morphine by one $\mathrm{CH}_{3}$-group.
The following table 2 shows the percentage crossactivity of DPC compared with other morphine RIA kits.

Tab. 2. Percent of cross-activity of RIA morphine kits of different producers*).

\begin{tabular}{llrr}
\hline Drug & DPC-Kit & Kit 2 & Kit 3 \\
\hline Codeine & 0.21 & 110.0 & 191.0 \\
Oxycodone & 0.05 & 0.2 & 3.1 \\
Morphine glucuronide & 0.22 & 80.0 & 30.0 \\
Hydromorphone & 0.55 & - & 12.3 \\
Diacctylmorphine & 2.16 & - & - \\
Dextromethorphan & 0.01 & 0.1 & 0.0 \\
Apomorphine & 0.09 & 0.0 & 0.0 \\
Hydrocodone & 0.12 & 0.2 & 11.0 \\
Dihydromorphine & - & - & 169.0 \\
Methadone & 0.05 & 0.1 & 0.0 \\
Meperidine & 0.07 & 0.2 & 1.2 \\
Cocaine & 0.05 & - & - \\
\hline
\end{tabular}

*) Data taken from a working instruction of DPC. They have been verified by our own analogous examinations.

In addition, these RIA analyses for morphine are burdened by the metabolic conversion of codeine to morphine by demethylation. This may lead to serious problems with interpretation. The morphine detected may either be taken up directly as morphine or heroin (heroin is metabolically deacetylated to morphine) or formed from larger amounts of codeine taken up earlier. This situation cannot be clarified by a second analytical method. One approach is to perform two investigations, one with a morphine-specific, and the other with an opiate-specific RIA kit, which detects both morphine and codeine. Interpretion of the results still presents fundamental problems, which are solved only if the result from the morphine-specific kit is somewhat higher than, or at the same level as, the result from the morphine/codeine kit.

Because of these problems, radioimmunological results that are not verified by other methods must be interpreted rather cautiously, to avoid false decisions, especially in forensic cases. Thus, morphine values up to $0.3 \mathrm{mg} / \mathrm{kg}$ hair must be neglected. With higher results (up to $0.7 \mathrm{mg} / \mathrm{kg}$ ) a drug abuse cannot be safely excluded. On the other hand, these values could be due to a massive abuse of codeine, producing relevant amounts of morphine by demethylation. With even higher values (up to $1.5 \mathrm{mg} / \mathrm{kg}$ ) a morphine or heroin abuse seems probable. A verification by $\mathrm{GC} / \mathrm{MS}$ analysis is recommended. With results higher than $1.5 \mathrm{mg} / \mathrm{kg}$ a drug abuse is very likely, especially when supported by further facts (28).

As stated above, forensic application of RIA analysis must be supported by a second independent method, as required by the Senatskommission für KlinischToxikologische Analytik of the Deutsche Forschungs- 
gemeinschaft (DFG). Recent comparative studies with mass-spectrometry showed similar qualitative and quantitative results from both methods (29). Lower values are mostly due to the presence of morphine. Confessions of accused drug addicts agreed with data derived from RIA analysis of their hair. On the other hand, despite the demand for a second method, it is highly probable that the suspected person has not taken drugs, if the result from RIA hair examination is negative. For screening purposes the RIA analysis of hair is to be prefered to the more expensive mass-spectrometry.

Furthermore it has been argued that, in analogy with trace elements, medicaments could be taken up by contamination from the surrounding air. It should be stated that drugs will generally not be found in the environment. Upon contact with hair, they will hardly penetrate it and not be bound by hair substance. The critical arguments appearing sporadically in the medical literature concerning the results of inorganic trace element analysis, cannot be applied to medicament detection in hair.

\section{Recent and Future Aspects of Hair Analysis for Medi- caments}

About ten years ago, Berg (30) in a review emphasized the signification of hair as an important specimen in foro. In his opinion, even a detailed morphological hair analysis is not sufficient for the certain identification of any individual. Additional chemical-physical examination for inorganic trace elements makes it possible to state/exclude the identity of an incriminated hair-owner with probability.

Since that time, the conventionally applied analytical methods have been improved markedly with respect to sensitivity and specifity, so that many identification problems have been solved. For example, two-dimensional protein electrophoresis distinguishes between different animal species. In special cases, this technique can be used to assign examined hair to a certain patient (31). Further classification is possible by estimation of organic medicaments and inorganic trace elements in hair. Analysis of such substances, taken up endogenously or exogenously, can be used in medical and toxicological studies (24).

Of special interest is the ability to detect a medicament taken more than half a year earlier. This is of "forensic importance, in tracing the "career" of a drugdependent person up to one year. Furthermore, it can be determined whether a proved uptake was over a limited period or continuous. In cases where a moribund hospitalized person survives for several days, chemical-toxicological estimations on corpses frequently give no result, the drug having been metabolized or excreted. In these cases, the only evidence that death is caused by drugs is given by hair analysis.

As psychiatric clinics and other' medical institutions concerned with rehabilitation of drug and medicament-dependent persons, hair analysis is essentially better suited for gaining the compliance of physician and patient than blood and urine analysis. Hair analysis can be performed two months later, and it gives a better orientation to the physician about the actual state of his patient than the conventional methods do, which have been applied more often. In addition, costs are substantially lower.

Phencyclidine has become an important drug in the simulation of true mental insanity. Hair analysis permits the separation of true insanity from phencycli= dine psychosis by recognition of the actual reasons for abnormal patient behaviour (24). In the USA, hair analysis has been successfully applied in a methadone-maintenance-programme. Thus, relapsed patients could be recognized without incurring high expense. At the start of a methadone treatment it is additionally possible to determine the percentage heroin consumption, and to apply an equivalent dose of methadone.

Hair analysis gains special importance at the supervision of pregnant addicted women. In phencyclidine addiction there is danger of development of infantile brain damage, which cannot be healed postnatally. Knowledge of the abuse is gained by hair analysis of mother and child (25).

Recently, in the USA, hair analysis had been applied to applicants for positions in institutes, industry and public authorithies. Most inconspicuously applied, these tests are used to vet applicants for positions, which for reasons of security and responsibility, cannot tolerate drug- or medicament-dependent persons. The future will tell whether such tests are appropriate. From the European point of view, the strategy is not to be rejected, and the outcome of the American excercise will be watched with interest.

These are a few of the aspects of the detection of medicaments and other organic substances in hair. In the near future, the method will certainly be perfected and analytically extended. It is a fascinating fact that hair analysis reveals events that have occurred in the past. It is hoped and expected that new diagnostic methods will be developed in this field. 


\section{References}

1. Valkovic, V. (1977) Trace Elements in Human Hair. Garland STMP Press, New York - London.

2. Arnold, W. (1980) Satellite Conference to the 8th Intern. Conference on Alcohol, Drugs and Traffic Safety. Umea, Sweden.

3. Arnold, W. (1982) In: Beiträge zur Diagnose und Therapie akuter Vergiftungen (Müller, K. R., ed.) Akadem. Verlag Leipzig, pp. 72-73.

4. Püschel, K., Thomasch, P. \& Arnold, W. (1983) Forens. Sci. Intern. 21, $181-186$.

5. Baumgartner, A. M., Jones, P. F., Baumgartner, W. A. \& Black, C. T. (1979) J. Nucl. Med. 20, 748 - 752.

6. Schaidt, G. (1975) In: Gerichtliche Medizin (Mueller, B., ed.) Springer Verlag Berlin-Heidelberg-New York, pp. $122-132$.

7. Lochte, Th. (1938) Atlas der menschlichen und tierischen Haare. Verlag Dr. Paul Schöps, Leipzig.

8. Lochte, Th. (1941) In: Handwörterbuch der Gerichtlichen Medizin (v. Neureiter, F., Pietrusky, F. \& Schütt, E., eds.) Springer Verlag, Berlin, pp. 327-336.

9. Anke, M. \& Risch, M. (1979) Haaranalyse und Spurenelementstatus. VEB Gustav Fischer Verlag Jena.

10. Heffter, A. (1915) Vjschr. Gerichtl. Med. 49, 194-199.

11. Schwarzacher, W. (1930) Münch. Med. Wochenschr. 34, 1430-1434.

12. Seifert, P. (1954) Arch. Toxicol. 15, 84-91.

13. Brinkmann, B. \& Lemke, J. (1979) Arch. Kriminol. 164, 93-100.

14. Brinkmann, B., Lemke, J. \& Lengfeld, R. (1979) Arch. Kriminol. 164, 167-171.

15. Forrest, I. S., Otis, L. S., Serra, M. T. \& Skinner, G. C. (1972) Proc. West. Pharmacol. Soc. 15, 83-86.
16. Klug, E. (1980) Z. Rechtsmed. 84, 189-193.

17. Arnold, W. (1984) In: Topics in Forensic and Analytical Toxicology. (Maes R. A. A., ed.) Elsevier Science Publisher B. V. Amsterdam, pp. 45-51.

18. Arnold, W. \& Püschel, K. (1983) J. Forens. Sci. Soc. 21, 82.

19. Arnold, W., Teichner, M. \& Püschel, K. (1982) In: Proc. XII. Congr. Intern. Akad. Gerichtl. Soz. Med. Bd. 2, Verlag H. Egermann, Wien, pp. 743-747.

20. Baumgartner, A. M., Jones, P. F. \& Black, C. T. (1981) J. Forens. Sci. 26, 576-581.

21. Radloff, H. (1983) Inauguraldissertation, Med. Fachbereich Universität Hamburg.

22. Baumgartner, W. A., Black, C. T., Jones, P. F. \& Blahd, W. H. (1982) J. Nucl. Med. 23, 790-792.

23. Suzuki, O., Hattori, H. \& Asano, M. (1984) J. Forens. Sci. $29,611-617$.

24. N. N. (1984) In: A Breakthrough in Medical and Forensic Sciences. Janus Foundation, Los Angeles, Research Report December.

25. Skramek, J. J., Baumgartner, W. A., Tallos, J., Ahrens, T. N., Meiser, J. F. \& Blahd, W. H. (1987) Amer. J. Psychiatry (in press).

26. Strüssmann, A. (1981) Ärztliche Kosmetologie 11, 119141.

27. Arnold, W. (1986) Toxichem + Krimtech, Number 42, pp. $12-13$.

28. Arnold, W. (1986) not published.

29. Arnold, W. \& Sachs, H. (1987) Vortrag 14. Süddeutsche Rechtsmedizinertagung in Stuttgart, 29./30. Mai 1987.

30. Berg, St. (1977) Arch. Kriminol. 159, 65-73.

31. Marshall, R. C., Gillespie, J. M. \& Klement, V. (1985) J. Forens. Sci. Soc. 25, 57-66.

Prof. Dr. Dr. Wolfgang Arnold

Forensische Laboratorien

Eckerkamp 96

D-2000 Hamburg 65 
